\title{
EL TEBEO, FUENTE PARA LA HISTORIA CONTEMPORANEA MEDIANTE LA INVESTIGACION PSICOSOCIOLOGICA
}

\author{
Federico Revilla*
}

Actualmente ya no es novedad reconocer al tebeo ${ }^{1}$ una categoría artística. Algumas historias del arte comienzan a dedicarle por lo menos referencias y alusiones, cuando no un capítulo propio, aunque inevitablemente corto e insuficiente. Se ha prescindido del criterio que para descalificar al tebeo como arte esgrimía la baja calidad de muchas de sus producciones: todos sabemos que se han embadurnado miles de kilómetros cuadrados de pintura execrable, que se han malgastado toneladas de material para esculpir pésima escultura, etc., etc., y nadie por ello hace dengues intelectuales a estas artes. Por otra parte, el elenco de dibujantes excelentes que se han consagrado al tebeo puede alinear nombres tan ilustres como los de Harold Foster, Alex Raymond, Milton Caniff, Burne Hogarth, Hergé, Guido Crepax o Uderzo, a los que podemos añadir, sin hacer patrioterismo barato, a los españoles Emilio Freixas, Jesús Blasco, Víctor de la Fuente, Enric Siò y Carlos Giménez, entre otros.

Sin embargo, aquí nos vamos a ocupar sólo lateralmente del tebeo en cuanto manifestación artística. Muy presente nuestra preocupación interdisciplinar, nos fijaremos principalmente en las aportaciones que el estudio de estas obras está en condiciones de efectuar a la Historia Contemporánea. El tebeo es, en efecto, un reflejo vivo de su tiempo: en cuanto producto de consumo, depende de los gustos de su público; y éstos, a su vez, se hallan condicionados por los demás factores determinantes de aquél (sociología, opinión pública, política, acontecimientos, etc.) La calidad estética viene sobreañadida, pero no afecta el valor documental del tebeo.

${ }^{1}$ Preferimos el término "relato gráfico", más preciso, au nque por razones de comodidad empleemos también "tebeo". Por lo demás, éste ha sido aceptado por la Real Academia Española de la Lengua. En cambio, rechazamos el anglicismo "comic", que sin embargo inunda últimamente la bibliografía sobre estas materias. 
Esta clase de investigación debe ser conducida mediante la técnica del análisis de contenido. Solamente en algunos casos concretos la crítica artistica puede aportar precisiones en la misma línea: p.ej., el despojo máximo propio del estilo de Schulz, en sus famosos "Peanuts", es un modo de concentrar la atención en el agobiado mundo interior de éstos, "haciendo patente así su desconfianza hacia las apariencias, que hallaremos continuamente formulada por sus personajes". ${ }^{2}$ O la desmaña, el total desapego de Perich hacia la obra bien hecha - que en su caso hubiera sido "la caricatura bien hecha" expresan su repudio de la sociedad, su anarquizante "Me importa un rábano", que él repite casi continuamente en la mayoría de sus chistes y dibujos. (Téngase en cuenta que en catalán, la lengua hablada por este dibujante, las expresiones anarquizantes equivalentes adquieren matices mucho más drásticos y significados mucho más crudos).

Las investigaciones que hemos realizado sobre el relato gráfico español de 1940-50 permiten apreciar en qué medida estas publicaciones pueden ser fuente - siquiera modesta - para la Historia Contemporánea.

\section{Homogeneidad histórica del decenio estudiado}

Para nuestros efectos, el período comprendido entre 1940 y 1950 es bastante homogéneo: la historia española queda paralizada en las consecuencias inmediatas de la guerra civil. La aceleración de la historia sólo comenzará a partir de 1951, con la aparición de los primeros turistas en nuestras tierras que entonces eran contemplados con asombro -, para alcanzar su apogeo en el decenio de 1960, que es, socialmente hablando, el período del gran vuelco. Social, que no políticamente, pues el régimen político imperante sólo evoluciona muy lenta, casi imperceptiblemente. Un trabajo de esta índole presentaría diferencias tales entre la manera de entender la vida unos y otros, por ejemplo, en 1960 e en 1968, que lo invalidarían parcialmente.

No es así en el marasmo de nuestra posguerra. La literatura oficial ha vuelto sistemáticamente la mirada atrás: se habla del imperio, se exhiben por doquier los símbolos del yugo y las flechas, así como el águila imperial. Un historiador tan vinculado al orden franquista como Ricardo de la Cierva no tiene inconveniente en reconocer que "los Austrias constituyen el lejano ideal de Franco". ${ }^{3}$ Semejante admiración confirma el paralelo psicológico que,

${ }^{2}$ Federico Revilla: Quince cuestiones de Historia Psicosocial del Arte, p.185. Editorial R.M. Barcelona, 1978.

${ }^{3}$ Ricardo de la Cierva: Historia básica de la España actual Rep. en Historia y vida, núm. 82, p.33. Barcelona, enero 1975. 
desde otra orilla política, traza Ramón Tamames entre el general Franco y el rey Felipe II: "Incluso es posible establecer un paralelismo entre ambos esta distas por su carácter de hombres reservados que desde un palacio extraur. bano y sin grandes contactos nı viajes exteriores dirigieron con puntillosidad los resortes del poder manejando a los hombres y reajustando no pocas inst 1 . tuciones, con una actitud frente a la historia bien constante en sus aspectos fundamentales". 4

El aislamiento español de 1940-50, explicado según una supuesta superioridad moral, recuerda mucho, ciertamente, la "cuarentena ideológica" impuesta por Felipe II. Tampoco durante los primeros años de Franco penetraban apenas ecos del extranjero. Recuerda Cirici Pellicer: "Todas las bibliotecas habían cortado las suscripciones a revistas extranjeras, porque las cosas extranjeras eran consideradas diabólicas".5 La arquitectura oficial es pseudoescurialense; la oratoria, hinchada, vociferante y hueca (males de los que, iay!, no se han curado todavia algunos políticos...). No extrañará, entonces hallar en los textos de los tebeos descripciones, frases e incluso imprecaciones altisonantes.

No deja de ser curioso que en semejante período de semiparalización histórica, desertización intelectual, pobreza y desaliento en la calle, aparezca una floración de tebeístas de primera fila. En concreto, la revista "Chicos" ha sido considerada por Luis Gasca el mejor logro de la historia del tebeo español. ${ }^{6}$ Ello valora más el esfuerzo de unos pocos, que luchando con toda clase de obstáculos (escassez de papel, contes, incultura y atonía populares, censura, consignas, etc.) lograron aquellos resultados. No siempre se ha hecho justicia - quizá también por razones políticas al papel desempeñado por Consuelo Gil Roesset, no sólo directora de "Chicos", sino infatigable descubridora de jóvenes valores. Muchos de ellos hoy están ya en la historia.

Nuestro trabajo se basa en cuatro publicaciones: Hipo, Monito y Fifi. Zas, TBO y El Gran Chicos.

\section{Contexto tebeístico: otras publicaciones de la época}

Hubiera sido bastante artificioso "aislar" unas publicaciones determi-

${ }^{4}$ Ramón Tamames: "La República. La era de Franco", p.360. Historia de España Alfaguara, vol. VII. Ediciones Alfaguara S.A. - Alianza Editorial S.A. Madrid, 1973.

5 Alexandre Cirici Pellicer: "La generaciò del mig", en Etica i Estética del anys 40-50. p.49. Asociación del Personal de la Caja de Pensiones para la Vejez y de Ahorros. Barcelona, 1973.

${ }^{6}$ Luis Gasca: Los "comics" en España, p.119. Editorial Lumen. Barcelona, 1969 
nadas, por muy representativas que fueran. Debemos, por tanto, aludir al menos a las publicaciones que formaron su entorno.

Tuvo un gran éxito el personaje "Juan Centella": el héroe fascista "Dick Fulmine", dibujado por Carlo Cossio. Se trata de un individuo de musculatura hipertrófica, chato y de facciones escuadradas, que sugieren lo más lejano de una delicadeza de sentimientos: "Juan Centella" es potencia, acción... y nada más. En efecto: un ideal de eficacia afín a la ética mussoliniana. Su gran aceptación en el mercado español - aun contando con la escasa competencia existente - constituye una pista más para comprender la situación moral del país. Ya que, si bien el estado era muy impositivo, su poder no llegaba hasta la coacción sobre la elección de compra personal: si los chicos elegían o preferían a "Juan Centella" era porque respondía a ciertas apetencias suyas, y no cabe exonerarles. El éxito de este personaje se prolongó muchos años, hasta después del derrumbamiento del fascismo italiano. Escribe Luis Gasca: "Naturalmente, al caer el movimiento político que lo sustentaba, fue retirado de todos los kioskos (de Italia). Pero en España, donde ya era famoso, (uno de los más populares héroes del tebeo europeo de nuestra historia, quizá el mayor) siguió siendo un ídolo, bajo el nombre de 'Juan Centella, el héroe hispanoamericano’. Se realizaron y dibujaron aventuras apócrifas que imitaban servilmente el estilo de Carlo Cossio, su creador. Y Juan Centella vivió una segunda y dilatada vida en la península Ibérica, hasta los años sesenta".?

"Jorge y Fernando", de Lyman Young, tuvieron también muy buena aceptación; así como "El hombre enmascarado", de Ray Moore. Colecciones ambas creadas en época anterior (respectivamente, en 1932 y 1936), que llegaban con retraso. Reflejaban una mentalidad colonialista.

Entre la producción nacional, hay que fijarse en dos de los mayores éxitos: Roberto Alcázar y Pedrín, de Eduardo Vañó, y El Guerrero del Antifaz, de Manuel Gego. Esta última serie de tebeos se publicó hasta 1966, pero ha sido objeto de reedición. En cuanto a Roberto Alcázar y Pedrín, probablemente no haya ejemplo igual de longevidad editorial. Este fenómeno obliga a cuestionar la supuesta evolución en los gustos del público español consumidor de tebeos. Tanto un autor como otro habían mostrado sobradamente durante los primeros años la limitación de sus recursos. Eduardo Vañó, que era un principiante torpe en su primer cuaderno publicado ("Los piratas del aire"), hizo progresos bastante rápidos en los meses que siguieron, para estabilizarse y anquilosarse a continuación en un dibujo de pocas líneas, eficaz, pero carente de garra e inventiva, exclusivamente preocupado - como los propios guiones - por los masivos repartos de puñetazos y golpes que eran el

${ }^{7}$ Luis Gasca: Tebeo y cultura de masas, p.122. Editorial Prensa Española. Madrid, 1966. 
atractivo de las aventuras. Manuel Gago, mejor dibujante, se adoceno también en la serie, forzado a un pluriempleo casi inhumano Pensemos que Gago dibujó también El pequeño luchador, Capitán España, El acróbata Terremoto, Aguilucho, As de Espada, Jim Alegrias, El Guerrillero Audas, Mosquetero Azul, Cruzado Negro y Tony y Anita, los ases del circo. aunque estos empeños menores se escalonasen en el tiempo, ¿ es posible mantener una calidad media aceptable con semejante cúmulo de trabajo?

Las dos series que nos ocupan ahora, muy dispares en estilo, repertorio argumental e incluso época de su ambientación, presentan no obstante el rasgo común de presentar junto a los respectivos protagonistas a sendos personajes infantiles: inseparable de Roberto Alcázar, el rubio Pedrín (en la práctica, Pedrín no tardaría en eclipsar a Roberto Alcázar en las preferencias de su público); inseparable del Guerrero del Antifaz, su escudero Fernando. Contrariamente a otros personajes infantiles de relato gráfico que hemos encontrado en nuestro estudio, éstos no tienen nada de independientes: todo lo contrario, son estrictamente referenciales a los protagonistas. A ellos se lo deben todo, incluso su mismo ser tebeístico. Algunos mal pensados han aludido a una eventual vinculación homosexual, pero ésta no se derivaría en ningún caso de su comportamiento expreso. En El Guerrero del Antifaz se mezclan a menudo elementos amorosos heterosexuales, casi siempre platónicos y desenfocados, como imponía la mojigatería de las directrices oficiales. ${ }^{8} \mathrm{La}$ cuestión podría ser algo vidriosa en Roberto Alcázar y Pedrín, ya que aquél es un célibe más bien deshumanizado que ignora a las mujeres; pero tampoco hay motivo sólido en la colección que justifique una interpretación semejante. Por poco que se examine, Roberto Alcázar es indiferente a las mujeres porque es indiferente a todo: su psicología es una penosa hoja en blanco.

Más allà del campo del relato gráfico, pues originariamente fue una colección de novelas de bolsillo, anotemos también el éxito masivo de $\mathrm{El} \mathrm{Coyo-}$ te, de José Mallorquí. El gran intérprete de este personaje, en cromos y en tebeos, fue el dibujante Francisco Batet.

\section{Hipo, Monito y Fifi}

Estos cuađernos son una animalandia, con inevitable referencia a Walt Disney, si bien Emilio Boix, el dibujante, dista mucho de su genio. La muestra estudiada comprende 24 unidades (años 1943-44), de las cuales 21 son cuadernos de aparición habitual, más un llamado "almanaque mensual", por una parte, y los almanaques de $1943-44$, por la otra.

${ }^{8} \mathrm{Cf}$. Enrique Barreiro: "El Guerrero del Antifaz, 6 una educación sexual de posguerra?". en Revista Española de la Opinión Pública, núm. 24, abril-junio 1971 
El promedio de viñetas en los cuadernos habituales ${ }^{9}$ es de $35^{\prime} 75$ : una extensión más bien breve. El total de viñetas en la muestra es de 1116 .

Toda la eficacia de los tebeos descansa en sus protagonistas. Boix sólo acierta a crear unos contados tipos de animales "personificados" o "humanizados", sin el carisma propio de los de Walt Disney, cualesquiera que sean los reparos de contenido que se puedan oponer a éstos. Sobresale Hipo sin lugar a dudas. Se trata de un personaje voluminoso - obviamente, un hipopótamo -: si vale un juego de palabras, su gracia consiste en carecer absolutamente de ella. Pesado, basto, bronco, todo lo estropea, es la encarnación misma de la torpeza, tanto física como mental. Su maciza figura señorea las viñetas. A su lado, "Monito" y "Fifi" debieron pensarse para dar el contraste de la pequeñez y la fragilidad. Pero también carecen del encanto que éstas pudieran prestarles. Sólo valen en cuanto contraposicón a "Hipo". Esta pobreza de ambos se hace más palmaria en "Fifi", que-no sólo es fez, sino adusta; en ningún momento logra Boix prestarle un toque de femineidad.

El análisis de contenido arroja un resultado claro: la violencia constante en estos tebeos, so capa de humor. Hemos registrado golpes, desastres y brutalidades en el cien por cien de las historietas que componen la muestra. Un resultado tan absoluto requiere ser matizado - está en juego su credibilidad -, por lo que a continuación pasamos a distinguir - junto a otros elementos temáticos - tres clases de violencia, a saber: violencia deliberada por los antagonistas (agresiones, bromas peligrosas, etc.), violencia casual y violencia debida a torpeza de la víctima (casi siempre, "Hipo").

La tabla que sigue ha sido confeccionada en base a unidades-viñeta. Debe referirse, por tanto, a la cifra total de 1116 viñetas de la muestra estudiada.

\section{Tabla I}

Violencia deliberada . . . . . . . 168 viñetas

Violencia casual . . . . . . . . 132

Violencia por torpeza ......... 29

Total . . . . . . . . . . . . 329

Ello supone un 29'51\% de viñetas de violencia.

El ingenio de los guiones, en términos generales, se reduce a urdir ocasiones para golpes y quebrantos. Ahora bien, así como en otros tebeos los desastres sobrevienen mayoritariamente por azar o por mala fortuna, aquí esta

\footnotetext{
${ }^{9}$ Se evitan los téminos alusivos a periodicidad, pues la legislación de la época no la contemplaba, de modo que estas publicaciones eran periódicas sólo oficiosa o inconfesadamente.
} 
motivación escasea, mientras que predominan las agresiones contra los individuos y, más ampliamente, las acciones encaminadas con deliberación a dañar.

En términos generales, la trama suele consistir en el enfrentamiento permanente de "Hipo" a "Monito" y "Fifí". Abusando "Hipo" de su tamaño, se suele mostrar prepotente y avasallador, aunque simplón. "Monito" y "Fifi", a la postre, le humillan debido a su mayor inteligencia, que no carece de ribetes sádicos. Lo cual no impide que, a rachas, sean muy amigos. Rasgo éste típicamente infantil: los niños pasan rápidamente de las efusiones amistosas al golpe limpio. Así son estos personajes: versátiles y crueles. Llegan a auténticos refinamientos: en una de las historietas, por ejemplo, "Hipo" ha sido atado a un poste y se ve arrastrado por un camión, tras perforar con su impacto una valla de madera; "Monito" contempla la escena y le dice bromeando: "iQuieres un buñuelo?".

Los tres protagonistas se asemejan, empero, en su comportamiento habitual: propio de niños mal educados y, encima, perversos. Pero, ison niños? En cuanto a "Hipo", Boix parece decirnos gráficamente que no lo es, pues con la mentalidad precisamente infantil que informa toda la serie puede asimilarse "grande" a "persona mayor". Como "Hipo", además, es el más fuerte, hay que aceptarlo - así lo hacía su público - como una persona mayor. En cuanto a "Monito" y "Fifo" visten como adultos: él suele lucir un sombrero. Pero sus juegos casi siempre son infantiles y no diagamos sus bromas. En cambio, su relación mutua se hace ambigua: a lo largo de la serie parece insinuarse que sean novios, aunque nunca se afirma expresamente. No obstante, en el relato gráfico titulado "Casa de huéspedes" aparecen con problemática propia de casados: "Monito" se queja de tener que coserse un botón y deciden alojarse en una casa de huéspedes para que "Fifí" no tenga tanto trabajo (!). "Ergo" conviven... Estas curiosas deducciones, que asombrarán a la gente actual, han de ser continuas para moverse en medio de la temática de aquellos años, en que ciertos temas, como el del contacto entre los sexos, eran tan celosamente vigilados que obligaban a hacer brumoso lo que de suyo es tan claro y $\tan$ natural...

Así como son infantiles las alternativas emocionales de los protagonistas, lo es igualmente la indiscriminación moral de estos relatos gráficos. Lo mismo que durante las primeras etapas de su vida el niño no distingue el bien del mal, el autor tampoco parece distinguirlo: dijérase que considera bueno todo lo que produce placer (concretamente, el placer de la diversión o de la risa). En este orden, son éstos asimismo unos tebeos esencialmente primarios. Quizá por ello los aceptasen los niños: se amoldan a su mundo. Pero los pedagogos nos dirán que se trata del mundo de sus primeras edades, pues el senti- 
do del bien y del mal no tardará en írseles desarrollando. ${ }^{10}$ Por consiguiente, a partir de cierta edad, la lectura de Hipo, Monito y Fifi debía resultar peligrosamente regresiva.

Los triunfos cruentos de los dos monitos sobre el hipopótamo, las sevicias a que le someten, sus bromas pesadas, cuando no dolorosas, podrían interpretarse como una compensación brindada a los pequeños lectores por las muchas ocasiones en que debían ser sojuzgados por sus superiores. Si precisamente los niños captan más la gravedad de una infracción respecto de un "mayor" (la misma infracción es para ellos menos grave respecto a un niño de su misma edad), según Piaget, ${ }^{11}$ estos daños causados al colosal "Hipo" habrían de ser entendidos con especial énfasis. ¿Y qué decir, si en vez de adoptar la perspectiva estrictamente pedagógica pasamos a la político-social? Una etapa de máxima represión, en que unos poderes vivenciados como aplastantes - el hipopótamo - acosaban a los menudos e indefensos ciudadanos corrientes. El ensañamiento de éstos respecto de la imagen de aquellos poderes se explicaría como una compensación. El individuo, aunque poquita cosa, puede reirse de la bestia amenazante... aunque sólo sea en los módicos tebeos que compra para sus hijos.

La quietud y falta de empuje propios de la época se reflejan en estos relatos gráficos mediante la ambientación de los mismos. No aparecen signos de vitalidad social: el entorno de los personajes corresponde generalmente a un estadio preindustrial. La vida es muy simple - parece desarrollarse en un pueblo, donde todo el mundo se conoce - y los individuos se muestran idilicamente libres: cambian de actividad (aunque actúan poco) o de distracción (cosa que les ocupa más a menudo), carecen de auténticos problemas (excepto los que ellos mismos se buscan) y su mayor interés consiste en pasarlo bien. Se respira un vago hedonismo, aunque trivial e ingenuo. Todo ello cuadra bastante bien con la actitud del combatiente, fatigado por un esfuerzo infecundo, que centra toda su atención en los pequeños goces cotidianos que le habían sido negados anteriormente.

La España que bosteza de Antonio Machado está bien interpretada, aunque probablemente nada distaba más de la intención del autor, sólo dedicado a divertir a un público sencillo. No hay rastros de afanes de reconstrucción, actividad ni progreso. El ocio es un valor omnipresente en estos tebeos. Incluso cuando los personajes trabajan, predomina el componente lúdico, en una desvinculación de toda necesidad material. Se aprecian mucho las golosinas: repetidas veces el premio en un concurso o en un campeonato consiste

10 José M. Quintana Cabanas: El niño en las distintas clases sociales, p.161. Editorial Marfil. Alcoy, 1970.

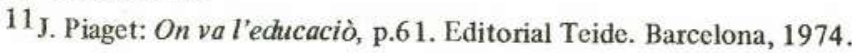


en un pastel espectacular. Ello responde no sólo a los intereses del niño, sino también a la realidad social de aquel tiempo, en que, efectivamente, un pastel era todavía algo excepcional, al alcance de muy pocos y por ello más deseable.

No hay rastro de poesía (como en las producciones de Disney), ni pretensiones didácticas (como en la fabulística). Apenas hay matizaciones caracterológicas, así como tampoco adolece por tanto de rudeza, hasta el punto de que ni siquiera puede hablarse de auténtico humor: lo que pudiera referirse a éste no pasa casi nunca de la sal gruesa de las peleas, bromas sangrientas y súbitas transiciones de conducta o, a lo sumo, recursos de muy basta picaresca.

Zas, subtitulada "Revista Nacional de la Sección de los Aspirantes de Acción Católica", fue un empeño que, pese a salir determinado por unos objetivos tan definidos, alcanzó un nível de calidad más que aceptable en su época. Baste decir que su promotor, Alberto Maqua, supo catalizar a unos jóvenes tan prometedores como Vicente Roso, Víctor de la Fuente, Luis Vigil, “Gabi", Moro, y José Laffond, todos ellos futuros grandes dibujantes, y entre los escritores Jaime Ministral Masiá.

La muestra estudiada comprende la colección completa de Zas, ésto es, los 16 números que se publicaron, a partir del correspondiente a la primera quincena de marzo de 1945 (sin fechar); el último correspondió al 28 de octubre del mismo año.

Puesto que Zas combinada - con loable intento - las páginas literarias con las páginas de tebeo, aquí nos hemos de atener solamente a éstas. Advirtiendo tan sólo que se mantuvo casi constante la relación proporcional entre unas y otras, con notoria ventaja para las escritas.

"El pequeño profesor Pin y su ayudante Freddy" es una página de "Gabi" (Gabriel Arnao), en el doble aspecto de dibujante y guionista. Es el suyo un humor del absurdo, en la línea nueva por entonces de La Codorniz. Hay que apreciar, por tanto, su inclusión en una publicación infantil, que suelen ser casi siempre conservadoras y por tanto muy reticentes a las novedades. El dibujo, muy sumario, emplea también algumas formas deshumanizadas, casi picassianas: el "pequeño chico Freddy" es una figura ovoide rematada en su ápice por una especie de pico, que también dará motivo a algunas ocurrencias; dos trazos a guisa de piernas terminan en unos gruesos zapatones, un enorme trazo representa la boca y dos pequeños toques los ojos. El "professor Pin", en cambio, posee forma humana, aunque grotesca. Superando la imaginable perplejidad de unos niños de su tiempo ante estos dibujos, "Gabi" construye unas historietas llenas de vivacidad y gracia, debidas en gran medida a sus guiones. En las 16 aquí analizadas no se repite un solo tema. Manteniéndose fiel a su estilo, da en cada ocasión un giro nuevo a las incidencias 
humorísticas, sorprende con recursos inesperados, etc. El diálogo es siempre divertido, con reminiscencias de Tono y los humoristas de su grupo. Por ejemplo:

- Doctor Pin, ¿está usted dormido?

- No contesta. Tendremos que despertarle para que nos lo diga.

Aunque generalmente, la gacia se basa en la acción, hay otros casos en que es exclusivamente verbal.

"Gabi" no deja de apuntar a veces ulteriores intenciones. Así, después de una serie de incidencias con un "hombre mecánico" que ha inventado el "profesor Pin" y que acaba emprendiéndola a golpes con él mismo, "Freddy" remata así la historieta:

- $i$ Le felicito, doctor Pin! iHa hecho usted una máquina maravillosa, perfecta! Es tan desagradecida como un ser humano de verdad.

Parecida calidad se mantiene en otras colaboraciones de "Gabi" en la revista Zas. El mejor elogio que se les puede dedicar es reconocer que no han perdido su gracia con el paso del tiempo.

El personaje de "Tito Bola", dibujado por José Madorell, es en cambio un intento que no llegó a cuajar. Pertenece a la amplia familia tebeística de los "niños autónomos", niños que no tienen padres o que actúan como si no los tuvieran. Evocan un paraíso ficticio de autosuficiencia. No sólo el autor ha eliminado todos los problemas de relación que comportaría para la serie la inclusión de unos padres, sino que ha hecho más: ha borrado el mundo adulto, en cuanto hostil, o por lo menos, ajeno... Ahora bien, la eliminación de ese mundo adulto es engañosa. Como no hay sucedáneo... resulta que los niños se ven obligados a conducirse como adultos. Es preciso hacer la compra, cocinar o reparar la avería de la conducción de agua... El precio pagado por "Tito Bola" y su hermanita "Fina Bola", lo mismo que tantos "niños adultizados" como ellos, es muy oneroso: para verse libres de los mayores, han de pechar ellos con sus responsabilidades. i Dónde queda, entonces, la supuesta felicidad? Porque, iłacaso puede ser de veras feliz un niño haciendo el papel de adulto?

Es notable que aparezca esta cuestión en una revista tan cuidadosamente dosificada y estudiada para los niños como era Zas. Ello le evitó cualquier arista. Sin embargo, queda planteada la inquietud subyacente acerca - nada menos - que del "ser niño". Que dicha cuestión preocupaba a los dirigentes de Zas se demuestra por la publicación en la propia revista de "El libro de la selva", cuyo protagonista "Mowgli" es uno de los más ilustres representantes literarios del mito del niño au tónomo. ${ }^{12}$

${ }^{12} \mathrm{Cf}$. Federico Revilla: Simbologia, arte y sociedad, pp.188-193. Bruño-Edebé. Barcelona, 1980. 
Habiendo cultivado el tebeo humorístico con tanta asiduidad como acierto (a las mencionadas hay que añadir las colaboraciones de Luis Vigil (Luis Alvarez-Vigil Escalera), Zas cuidó mucho también el género histórico, desarrollado en la forma de tebeo apoyado en textos secuenciales. La sección "Episodios históricos", a página entera, sólo dejó de publicarse en un número de la revista.

Como quiera, la elección de los temas no destacó por su amplitud de miras:

\section{Tabla II}

Hechos de armas........... 13

Hecho de armas no consumado ...... 1

Martirio ............... 1

Domina en absoluto, pues, la violencia guerrera. La historia se entiende todavía como sucesión de hechos bélicos. Más aún, entre los trece hechos de armas se cuentan cinco (es decir, un tercio del total de la serie) que carecen de una relevancia apreciable: no ejercieron influencia histórica decisiva, ni tampoco ofrecen - en otro orden - un relieve aventurero que los haga dignos de recordación. Se trata de hechos de armas que no tienen más valor que tales: el combate por el combate...

Pero la elección de los temas no solamente es discutible en cuanto al fondo, sino también técnicamente: algunos temas son demasiado amplios para el reducido espacio de que se dispone y su exposición resulta atropellada (encerrar "La conquista del Pacífico" i en seis viñetas!). Para esta extensión se requería un tipo de episodio breve, emocionante y completo en sí mismo, como el del cabo Noval ("Sacrificio heroico", en el núm. 15). Degraciadamente, con la excepción de este episodio no se acertó con la justa proporción entre el hecho histórico y el espacio de una página.

Los textos son muy desiguales a lo largo de la serie, pero generalmente adolecen de semejante reducción a límites tan estrechos. Es frecuente la grandilocuencia, algunas veces ya en el mismo título: "i Por Dios y por el honor de la bandera!” (núm. 5), “iLoor a Pedro de Valdivia!” (núm. 16). Precisamente este último guión bate marcas de determinada tendenciosidad al exponer la historia. Basten los siguientes ejemplos:

"En vista -le la injustificada agresión..." (Por supuesto, son los indígenas quienes agreden injustificadamente).

"Así surgió la hermosa ciudad de Santiago de Chile, como una de las mayores glorias de la Madre España".

"Muchos indios son rudos y obstinados y no toleran la civilización europea..." 
Se finaliza con una auténtica apoteosis: "La barbarie se ha adueñado del capitán-héroe, el único superviviente. Los indios le han cortado los brazos con afiladas conchas de mar. Los muñones chorrean sangre. Entre tanto, los indios van asando sus miembros en la hoguera. Al olor de la carne quemada saborean ya el festín. iBrazos del bravo capitán que tan bien supieron manejar la espada y la lanza por España!..."

Reconozcamos, empero, que no todos los guiones fueron tan abusivos como éste. En "La conquista del Pacífico" no hay triunfalismos, pero el estilo es pueril y poco trabajado (núm. 12). Otras veces se mezcla un indigesto teologismo histórico (“iPor Dios y por el honor de la bandera!"), como en estas frases:

"iDios protege a quienes luchan por la cruz y el honor de su bandera!"

"Pero Dios ayuda una vez más a rechazar el ataque".

"iNunca un español se rinde a un enemigo de la cruz!"

Por otra parte, alguna vez aparecen incitaciones a la más escueta violencia física ("El desquite de los almogávares", núm. 10):

'IDejad el botín y matad!'”

No aparecen en toda la serie otras virtudes "históricas" que la fiereza, el arrojo o la temeridad. Ni siquiera el único episodio que no es directamente bélico ("Los cuarenta mártires de Sebaste", núm. 7) presenta unas virtudes propiamente cristianas, aunque lo pretende: se ha enfocado también desde el ángulo de la violencia - en este caso, violencia padecida - y lo que se exalta es el aguante de los mártires, pero no la vivencia profunda de su fe. Eso sí, habiendo cuidado que los dibujos evitasen los detalles de crueldad: ésta se describe, pero no se ha permitido que se compruebe visualmente.

En suma, los "Episodios históricos" acusan demasiado la tensión de una guerra que en tiempo de Zas ya empezaba a quedar atrás. El factor belicista no sólo mantiene la sección, sino que fundamenta la suposición de que sea el motor de la historia. Fallo tanto más grave, puesto que lo hallamos en un equipo tan responsable como el que realizaba esta revista.

Vicente Roso comenzó su colaboración en el núm. 6 para ilustrar las entregas de "El libro de la selva". En el núm. 7 se inició la publicación de "Las hazañas de Teseo", relato gráfico que continuaría durante los siguientes números, hasta quedar interrumpido con la desaparición de la propia revista. En 1945 tenía Roso 24 años, ya había hecho sus primeras armas en "Flechas y Pelayos" y "Maravillas", pero no era todavía el seguro dibejante que posteriormente se reveló. El título de "Las hazañas de Teseo" ahorra explicaciones. De entrada, el guionista hubo de vérselas con un punto turbio: el origen de su héroe. Pero lo resolvió rápidamente haciendo declarar al rey Egeo: "Nuestro matrimonio debe permanecer secreto". Expeditiva manera de sacramentalizar - "para uso de Aspirantes" - una vulgar relación sexual mitológica. Cuando 
se manipulaba impávidamente la historia, icuántos menos escrúpulos se sentiría al manipular la mitología pagana!

\section{Tabla III}

Sobre un total de 88 viñetas que llegaron a publicarse, hallamos la siguiente distribución de los motivos principales:

Violencia entre personas . . . . . . . . . . . . . 14

Alarde de agilidad e o de fuerza física en general . . . . . . . 22

Total de manifestaciones de potencia física . . . . . . . 36

Se trata nada menos que de un $\mathbf{4 0 \%}$ de las viñetas publicadas. El relato insiste, pues, sobre este aspecto determinado, arrinconando los demás que hubieran podido valorarse. Cierto es que en la propia tradición helena las gestas físicas de Teseo le valieron su gran popularidad: hay que reconocer que este tratamiento no traiciona del todo los orígenes argumentales. Con todo, el guión - simplesmente correcto - desluce la leyenda, en el sentido de restarle grandeza: precisamente en cuanto se empeña en hacer descender a Teseo a una serie de alardes inútiles. Lástima que la interrupción nos impidiera conocer como resolvía el guionista los momentos cruciales de la leyenda - el encuentro y el amor con Ariadna - o cómo exculpaba al hérce de su responsabilidad al deshacerse de ella poco más tarde en la isla de Naxos.

La elección de Teseo no se hizo caprichosamente: éste encarna, según los dibujos de Roso, al muchacho limpio de cuerpo y de espíritu, sano e invencible, deportista, generoso, casto, que los responsables de Zas querían proponer como ideal a sus lectores. Hay que agradecer el buen gusto de no haber hipertrofiado la apariencia de sus músculos, bastando para mostrar su eficacia el continuo alarde que hace el héroe de su vigor.

Por supuesto, este arquetipo bello-bueno no es imitable. Le falta, sobre todo, verismo en las aventuras que se le hace protagonizar, muy lejos del ambiente de los muchachos a quienes tenía que servir como modelo. Su doble encuentro con unos enemigos "gigantes" confirma la inverosimilitud del medio donde actúa e imposibilita uma identificación práctica.

Con todo, Teseo es coherente con el contexto intencional de la revista. En efecto, se pretendía entonces "heroizar" a los jóvenes, en vez de dotarles de los medios para desenvolverse en la vida normal como unos ciudadanos y unos cristianos consecuentes. Esta tendencia se expresa, por ejemplo, en el texto de un anuncio que publicó también Zas (contracubierta núms. 3 y 4 ). Decía así, nada menos: ¿QUEREIS SER HEROES? - He aqui un libro que os enseñará a serlo. La vida de dos muchachos españoles, héroes y mártiros. La vida de SAN PELAYO y SAN ZOILO. Pese a su brevedad, el anuncio no 
puede ser más denso. Obsérvese, entre otros rasgos, la triple adjetivación. Son tres los valores propuestos como gloriosos: españoles, héroes y mártires.

Por el camino del héroe se llega al superhombre... A este punto llegaron muchos tebeos. El superhombre carece de rasgos comunes con lo que pudiera ser una antropología cristiana. Es doblemente sugerente, entonces, advertir cómo desde una publicación confesional se enfilaba una orientación tan peligrosa, si bien con el mejor ánimo formativo.

Por lo demás, esta revista adolece en sus restantes secciones de la misma desatención a la vida real. Incluso la sección titulada "Aspirantes" - gráfica, pero no en relato gráfico -, que pretendia precisamente considerar la problemática del niño, acusa, con el pietismo de la época, una completa falta de visión acerca del ambiente donde el propio niño debía moverse.

\section{TBO}

La publicación decana de la prensa infantil española cosechó muchos lauros a lo largo de su historia. Lauros justificados en cuanto a "duración", "resistencia" o "fidelidad a sí misma". Nuestra investigación ha demostrado, sin embargo, que no lo serían si los méritos elogiables hubieran de ser el acierto pedagógico o la adecuación al mundo infantil que "TBO" se proponía servir.

La muestra estudiada es satisfactoria: se trata de la colección completa de 54 cuadernos de $T B O$ correspondientes a los años 1947-49. La datación se ha efectuado por referencia a los almanaques respectivos y dada la fiabilidad - de la cual respondemos - en la custodia y orden de dicha colección. Puesto que TBO es una revista exclusivamente de historietas - su nombre ha pasado a ser substantivo del género -, consideraremos en un primer "Cuadro general temático" las unidades-historieta. Así pues, la frecuencia relativa de cada uno de los temas aludidos vendría dada por su proporción respecto de 54 (el total de cuadernos que componen la muestra).

\section{Tabla IV}

a) Cacerías, viajes y aventuras en países remotos, exotismo:

Serie "Eustaquio Morcillón" . . . . . . . . . . . . . 40

Otras historietas sobre estos temas . . . . . . . . . . 42

Total "Cacerías, viajes y exotismo" ... . . . . . . . 82

b) Inventos: TBO".

"El profesor Franz de Copenhague" . . . . . . . . . . . 21 
Otras historietas sobre inventos, con consecuencias jocosas . . . 14

Total "Inventos" . . . . . . . . . . . . . . . . . . 66

c) "La familia de Don Ulises" . . . . . . . . . . . . 43

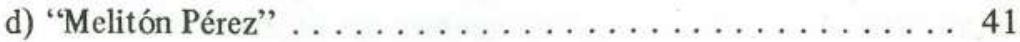

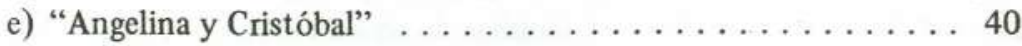

f) Niños que se divierten a costa de los mayores:

Diversión más o menos inocente o maligna, sin más . . . . . . 18

Diversión con declarada intencionalidad vengativa . . . . . . 15

Total "Niños que se diverten a costa de los mayores" . . . . . 33

g) "Visiones de Hollywood" . . . . . . . . . . . . . . 31

h) Nuevos ricos:

Historietas dedicadas directamente a ridiculizarles . . . . . . 8

Meras alusiones a nuevos ricos en otras historietas . . . . . . 14

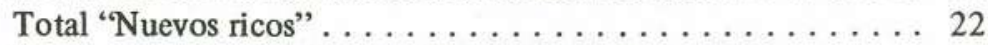

i) Problemas con animales o mal entendimiento con ellos .... 21

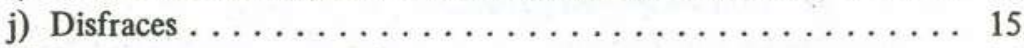

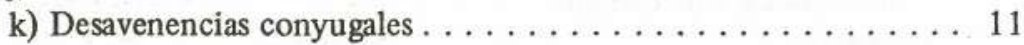

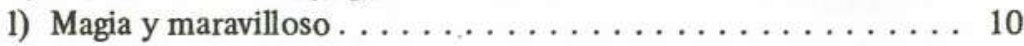

m) Alusiones peyorativas a la suegra $\ldots \ldots \ldots \ldots \ldots \ldots$

Durante la época que estudiamos, TBO está muy definido por la personalidad de su principal dibujante, Marino Benejam. Hasta ahora no se ha hecho la debida justicia a este dibujante, que, prácticamente encerrado en los estrechos límites de la revista y de la España de su tiempo, no consiguió una fama que quizá en otras circunstancias hubiera ganado. Benejam confiere a $T B O$ un estilo gráfico propio, muy fiel a la observación de la realidad - por lo que su valor documental es alto -, que matiza con un humor benévolo. Prácticamente eclipsa a los demás colaboradores, entre los que empieza a destacar un Muntañola juvenil, trabajando aprisa y sin esmero, y a la inversa un Ricardo Opisso decadente, que sólo tiene el nombre del espléndido dibujante de su juventud, parangonable como tal entonces, y sin demérito, con $\mathrm{Pi}$ casso, Nonell y Casas. Es una comprobación penosa para un historiador del arte repasar lo que Opisso llegó a hacer para malvivir, cuando había estado dotado para llegar a tanto... Por lo demás, TBO reaprovecha viejos materiales de Louis Forton, ya fuera de su época, y emplea a una reducida serie de modestos segundones, como Urda, Tínez y otros.

Hoy cualquiera sabe que el logro más típico de $T B O$ fue la serie de "La familia de Don Ulises", que se ha hecho llegar hasta fechas más tardías, fallecidos primero su guionista original, Joaquín Buigas, copropietario de la revista, y más tarde, ya retirado, su dibujante creador, el infatigable Bonejam. Que la posterior "familia de Don Ulises" fuera una especic de café con leche sin 
leche ni café no influye para nada en nuestro trabajo, que capta la creación precisamente en sus momentos iniciales, en su frescor primerizo. Se trata de un excelente espécimen de familia española de la pequeña burguesía: no sólo su mobiliario y ambientación, sino también sus objetivos y sus preocupaciones son los propios de muchas familias de aquella clase en la época. Pero hasta aquí llega su interés documental: porque, más allá de la captación de estos datos con la escrupulosidad de Benejam, sobreviene la distorsión humorística. Y ésta ofrece ya otro panorama, que será revelador también, pero en muy diverso orden. La cuantificación de los recursos hilarantes de esta serie (sobre un total de 43 historietas) arroja el siguiente resultado:

\section{Tabla V}

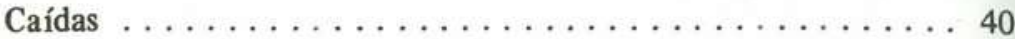

Golpes, coces, corneamientos, pinchazos y otros accidentes .... 26

Caídas de "Don Ulises" en particular . . . . . . . . . . 23

Confusiones y frustraciones $\ldots \ldots \ldots \ldots \ldots \ldots \ldots \ldots$

Mojaduras . . . . . . . . . . . . . . . . 14

Otros desastres (fuego, roturas, ataque de avispas, etc.) . . . . . 9

Sustos ...................... 6

Pérdida de la peluca de la abuelita $\ldots \ldots \ldots \ldots \ldots \ldots$

Persecuciones (en cuanto víctimas de las mismas) . . . . . . 5

Ensuciamientos ........................ 2

Pero hay algo más: la relación del matrimonio es pésima. La esposa se dirige al pobre "Ulises" demasiadas veces en términos hostiles. Esto se hizo tan llamativo en un primer examen que nos movió a una cuantificación especial. El resultado es harto elocuente, aun distinguiendo dos grados en la animosidad del ataque verbal:

\section{Tabla VI}

Ataques verbales leves ..................... 34

Ataques directamente insultantes. . . . . . . . . . . 24

Total ataques verbales $\ldots \ldots \ldots \ldots \ldots \ldots . \ldots \ldots$

Estos datos bastan, por el momento, para advertir que "La familia de Don Ulises" no es un ejemplo que digamos de humorismo formativo. Efectivamente, la figura del padre no sólo es ridiculizada sitemáticamente, sino que se convierte en una especie de chivo expiatorio que carga sobre sí todas las culpas del grupo familiar. Desde luego, "Don Ulises" es un padre de su tiempo, exagerando su omnirresponsabilidad. En la familia nadie más decide, sino 
él. Pero como es corto, bonachón, torpe, crédulo, etc., no pueden sino seguirse los desastres que quedan cuantificados en la tabla V. La esposa carece de personalidad: no digamos de decisión... Sólo existe "respecto de" él: mas para hostilizarle y zaherirle. Aquí no se trata ya de la freudiana sublevación de la horda primordial para asesinar al padre. El significado es menos cruento, pero no menos duro: no se da muerte al padre, pero se le rebaja, se la desprestigia y se le hunde. Por lo demás, "Ulises" no recibe compensación alguna. Se han eliminado los momentos felices en la existencia de la familia: no hay un solo rasgo de cariño, comprensión, gratitud ni apego a su persona; jamás su esposa le hace una caricia, ni los niños juegan con él. La familia resulta así un grupo desacogedor e inhóspito, como una red donde el infeliz sujeto cazado no tiene más remedio que resignarse a aguantar desdichas.

Por si esta exégesis pareciera un tanto parcial, queda confirmada por el estudio correspondiente a la serie de historietas de "Angelina y Cristóbal", de Muntañola. En este caso, no hay clan familiar, sino tan sólo pareja. Pero también el marido es blanco de una sátira, que se hace monocorde e invariable. Muntañola como guionista no hace alarde de una inventiva despierta, pues de tal modo se repite.

\section{Tabla VII}

Comicidad por desdoro, ridículo o minusvaloración de "Cristó-

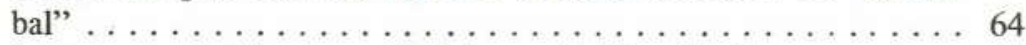

Lances a costa del volumen o del peso de "Angelina" . . . . . . . 7

El total de historietas analizadas es de 40 . Se ha abusado de las consecuencias del hallazgo gráfico inicial de la desproporción volumétrica entre la pareja. Esta es la clave de su significado. Las características somáticas de "Angelina", que es corpulenta y rotunda de turgencias, contrastan con "Cristóbal", menudito y apocado. No hay encono contra él, sino una sonrisa entre cordial y conmiserativa. Compárese, no obstante, esta actitud con la que requería la dignidad de un "cabeza de familia" en la época que se estudia.

En el apartado de "Niños que se divierten a costa de los mayores" (tabla IV), con la no desdeñable cantidad de 33 historietas en la muestra, hemos distinguido también dos grados:

\section{Tabla VIII}

Travesuras en diversos aspectos

(diversión más o menos inocente o maligna, pero sin ulterior alcan-

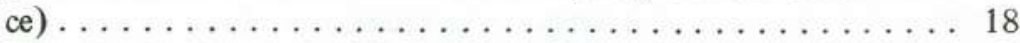

Diversión con finalidad vengativa . . . . . . . . 15 
Hay que reputar inquietante la frecuencia del tema vengativo respecto de los mayores. Dicha frecuencia viene a coincidir, en sus objetivos - por supuesto, no deliberados -, con el sentido demoledor de la familia registrado en los casos anteriores.

Uno de los escasos motivos en que $T B O$ sintonizó con la actualidad de su tiempo es su fobia a los "nuevos ricos": se trataba de una clase nueva, que prosperaba a favor de las dificultades económicas del momento. Se ridiculizan sin piedad su grosería, su orgullo, su prepotencia y su materialismo (aunque éste difiere sólo en apariencia del propio materialismo de la clase media apurada). Mucho más leve era la sátira contra el rico no zafio, sino refinado, vehiculada en una serie que no llegó a prosperar: "Informaciones rápidas de nuestro repórter gráfico Sr. Benejam”. En sus primeras historietas el protagonista era "el millonario Muñiz". Pero dado que entonces se consideraba en Barcelona el potentado más representativo a un apellidado Muñoz, no se tardó en cambiar el apellido del personaje, que pasó a ser "el millonario Ruiz". Podemos preguntarnos si fue una medida de precaución por parte de los propietarios de la revista o bien si intervino alguna presión o gestión más o menos delicada por parte del muy poderoso Muñoz de la vida real.

$\mathrm{El}$ estudio de $T B O^{13}$ nos ha conducido a detectar algunas constantes, no sorprendentes en cuanto tales si se tiene en cuenta que Buigas era el guionista casi único. ¿ $\mathrm{H}$ Hasta qué punto estas constantes responden al espíritu burgués catalán?/¿En qué medida dependen de la circunstancia histórica? Mientras preferimos dejar la primera pregunta entre sus interrogantes, podemos en cambio responder a la segunda, ya que hemos comprobado que TBO se mostró casi impermeable a las circunstancias, siendo sus número de la posguerra análogos en contenido, por no decir casi idénticos, a los del período inmediatamente anterior; y se observó posteriormente que continuó luego igualmente en parecida línea, so pretexto de explotar sua éxitos humorísticos.

Hemos hallado en los personajes de TBO

a) Un predominio de lo apariencial, un afán de poseer. Se trata de poseer generalmente bienes humildes, que informan sobre el bajo nivel adquisitivo de la época.

b) Una importancia concedida al "?Qué dirán?", una supervaloración de la opinión ajena, que igualmente contribuye a difuminar lo que el individuo debe realmente ser.

c) La muy negativa visión del matrimonio, que sin embargo no afecta la condición maciza de la familia. Ni por un momento se insinúa un revisionismo

${ }^{13}$ Para más detalles sobre este estudio en particular, cf. Federico Revilla: "Un estudio psicosociológico sobre TBO", en Prensa Infantil y Educación. Seminario de Sociología de la Educación. Publicaciones de la Universidad de Barcelona, 1981. 
del matrimonio que sólo mucho más lejos pudiera conducir a unas primeras nociones de separación del mismo. El matrimonio - parecen sobreentender los propietarios de TBO - "es" eso: insultos, befas, catástrofes; pero no se plantea que pudiera ser otra cosa o evolucionar hacia ello.

d) Una incapacidad para la fantasía poética, que se pone de manifiesto en las historietas que hemos englobado bajo la denominación de "Magia y maravilloso".

e) Frecuencia en los contenidos de frustración y desencanto.

f) Un subrepticio, involuntario (¿acaso subconsciente?) anarquismo, que induce a atacar a las personas entonces revestidas de autoridad (el padre, el marido, el tío); nunca, por supuesto, los agentes de la autoridad pública (el policía, el guardia, el funcionario), en lo que la censura hubiera sido implacable.

Si se piensa que $T B O$ ha sido considerada durante mucho tiempo una publicación recomendable para los niños - incluso ciertos organismos oficiales lo han reconocido asi ${ }^{14}$, los resultados de nuestro análisis de contenido no sólo resultan llamativos, sino paradójicos.

\section{El Gran Chicos}

Quiso ser El Gran Chicos una especie de decantación y plenitud de los resultados obtenidos, previamente, a lo largo de varios años, por la revista Chicos. El mismo título contiene una referencia a sus pretensiones de autosuperación. Hallamos, ciertamente, en El Gran Chicos los méritos de su hermano primogénito; si bien no le acompañó el mismo éxito en el mercado, acaso por razones de precio, entonces algo elevado para las posibilidades del adolescente medio.

La muestra ha sido una colección completa de El Gran Chicos compuesta por 33 números: concretamente, 9-41 (julio de 1946 a julio de 1949). A ella añadimos los cuatro almanaques de Chicos correspondientes a 1946, 1947, 1948 y 1949, que con tanta o mayor razón pretenden ofrecer lo mejor de que es capaz el cuadro de colaboradores de la casa. Como en el caso de Zas - cuya idea editorial comparte bastante la presente revista -, dejamos a un lado las páginas literarias para fijarnos precisamente en las de relato gráfico.

${ }^{14}$ En esta línea, el ministerio competente llegó a titular "Premio Joaquín Buigas" una de las distinciones encaminadas a fomentar una prensa infantil idónea. $\mathrm{El}$ autor de este trabajo no puede reprimir un suspiro de alivio al recordar que se le concedió el "Premio Nacional de Narraciones Literarias Infantiles y Juveniles" en 1975, es decir, precisamente antes de adoptar aquella denominación. 


\section{Tabla VIII}

El cuadro general temático de $\mathrm{El} \mathrm{Gran} \mathrm{Chicos} \mathrm{en} \mathrm{la} \mathrm{muestra} \mathrm{estudiada}$ queda del modo siguiente (las cifras que se indican aluden al número de viñetas de cada relato gráfico):

\section{Aventuras}

a) Aventuras en países exóticos:

"Los guerreros del Lago Verde" (incompleta) . . . . . . . . 140

"En las selvas oceánicas" (Incompleta) . . . . . . . . . 45

"La reina de Tanit" . . . . . . . . . . . . . . . . . 129

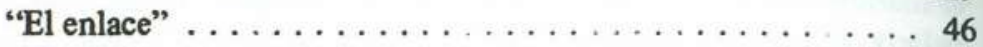

"El valle de las estatuas" $\ldots \ldots \ldots \ldots \ldots \ldots 61$

"La redomita de plata" . . . . . . . . . . . . . . . 57

"El ídolo escondido" . . . . . . . . . . . . . . . . 57

"Los siete altares de la Sapta Mata" . . . . . . . . . . . . . . 4 47

"Siguiendo a un proscripto" (sic) . . . . . . . . . . 65

"El templo de Siva" . . . . . . . . . . . . . . . 56

b) Detectives, "gangsters", espionaje, bajos fondos, etc.

"César Cris, detective privado" . . . . . . . . . . . . . . 127

"Cita con la muerte" . . . . . . . . . . . . . . . . . . . 89

"John Harrington" . . . . . . . . . . . . . . . . 60

"Benny Bomb, el detectivito" . . . . . . . . . . . 44 46

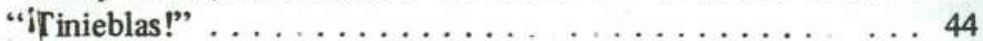

"Jack Logan" . . . . . . . . . . . . . . . . . . 63

"El dardo chino" .................... . 60

c) Oeste americano

"Pistol Jim" (incompleta) . . . . . . . . . . . . . . 62

"Astucia contra crimen" . . . . . . . . . . . . . . . . 27

"La pàntalla de los diablos rivales" . . . . . . . . . . . . . . 34

"La cárcel de la Garganta de los Esqueletos" . . . . . . . . . . 35

"El traidor" . . . . . . . . . . . . . . . . . . 59

"El cazador de caballos" ... . . . . . . . . . . . . . 57

Cuto en "Una del Oeste" . . . . . . . . . . . . . . 52

d) Fantaciencia

"Cinco hombres" ....................... 57

"Misterio en el mar" ..... . . . . . . . . . . . . . 56 
E1 Tebeo, Fuente para la Hist oria Contemporánea ...

"El mundo solitario" . . . . . . . . . . . . . 56

"El duende de Manhattan" ... . . . . . . . . . . . 55

"Cuto en el Lago de la Muerte" . . . . . . . . . . . . 42

e) Guerra

"Cuto en Nápoles" . ..................... 56

"Cuto en el junco de Sing" . . . . . . . . . . . . 71

f) Aire

"Máscara Roja" . . . . . . . . . . . . . . . 35

"El portaaviones aereo" . . . . . . . . . . . 34

g) Deporte

"Lucharé por ti" . . . . . . . . . . . . . . 69

h) Aventuras con ambientación historizante

"El demonio blanco"

\section{TOTAL “AVENTURAS”: 2.080}

\section{Humor}

Episodios humorísticos de "Cuto" . . . . . . . . . . . . . . . 249

Idem. de "Anita Diminuta" . . . . . . . . . . . . . . . . 127

Agencia "I.D.I.O.T.A." . . . . . . . . . . . . . . . . . 376

Varios . . . . . . . . . . . . . . . . . . 108

TOTAL "HUMOR": 860.

El panorama de $\mathrm{El} \mathrm{Gran} \mathrm{Chicos} \mathrm{en} \mathrm{sus} \mathrm{páginas} \mathrm{de} \mathrm{tebeo} \mathrm{está} \mathrm{dominado}$ por la creciente personalidad de Jesús Blasco, que iniciaba entonces la que había de ser su arrolladora carrera. Su creación más celebrada fue - y es "Cuto", un típico muchacho autónomo que corre toda clase de aventuras. Es sabido, porque lo ha recogido Luis Gasca, ${ }^{15}$ que la personalidad y los rasgos fisonómicos de "Cuto" le fueron sugeridos por su hermano Alejandro, cuando tenía la edad del pequeño héroe. En cambio, no se ha dicho todavía que otro de los personajes de Blasco, "Anita Diminuta", fue también copiado de la familia: concretamente, del menor de los hermanos, Augusto, cuando te-

15 Luis Gasca: Los “comics" en España, p.119. 
nía poco más de un año, a cuya fisonomía Jesús añadió las trencitas típicas de la niña.

Jesús Blasco escribía entonces sus propios guiones. Por consiguiente, las aventuras de "Cuto" son enteramente suyas. Así como la decisión - discutible - de convertirle en protagonista de historietas cómicas, lo cual llevó a cabo precisamente en "El Gran Chicos". En efecto, el héroe invencible es reducido en ellas por su propio autor a una serie de incidencias contradictorias: fallidas, frustrantes o incongruentes. Se trata de una desmitificación del héroe. Blasco nos dijo que la había acometido conscientemente, entendiendo que los grandes personajes tienen también defectos y sufren fracasos. Su idea de lanzar, pues, a un "Cuto cómico" cuando ya estaba consagrado como aventurero triunfador obedeció a la voluntad de quitarle importancia. No se trata de juzgar aquí sobre el acierto de esta determinación. Solamente debemos dejar constancia de que, en realidad, resultan, no las dos caras de un mismo personaje, sino dos personajes diferentes con la misma apariencia física. El "Cuto" aventurero sale airoso, actúa como un adulto, disfruta de plena seguridad; mientras que el "Cuto" humorístico falla, se equivoca, queda en ridículo o es humillado por enemigos exiguos.

Nos conviene fijamos en el "Cuto" aventurero. El otro apenas tuvo éxito. Quizá el público sintió aversión a reconocer vencido a su héroe favorito... A lo largo de muchos años, Blasco hubo de situarle en los escenarios y situaciones más dispares: por lo que, en panorámica, abundan los anacronismos (lo mismo aparece en el "Far-West", en una ambientación propia de finales del pasado siglo, que durante la segunda guerra mundial o en presente de 1945-50). Sus compañeros de aventura son despachados a veces con parecida indiferencia: pueden morir en la acción, sin demasiado quebranto para ésta (“Cuto en Nápoles"), o bien aparecer fugazmente en una relación ambigua (Isabel, en "Cuto en el Lago de la Muerte", debe ser su prima para evitar el 'escándalo' de verles en una excursión ambos solos). En suma, los relatos son rabiosamente cuto-céntricos: sólo importa él.

Por lo demás, no se suele incurrir en exageraciones sobre fuerzas o condiciones físicas: "Cuto" es un adolescente. Hay que justificar determinados hechos (en "Cuto en el Lago de la Muerte" se le atribuye una capacidad cardiocirculatoria fuera de lo común), pero la elección de la edad del protagonista ha frenado posibles excesos en este orden.

Sobre la violencia en estos relatos gráficos, nos remitimos a su cuantifi- 
El Tebeo, Fuente para la Historia Cu. temporánea ...

cación, ${ }^{16}$ que nos evita el peligro del subjetivismo:

\section{Tabla IX}

\begin{tabular}{|c|c|c|}
\hline $\begin{array}{l}\text { Número } \\
\text { total de } \\
\text { viñetas del } \\
\text { relato } \\
\text { gráfico }\end{array}$ & $\begin{array}{l}\text { Número } \\
\text { viñetas con } \\
\text { acciones de } \\
\text { violencia }\end{array}$ & $\begin{array}{c}\text { Número } \\
\text { viñetas con } \\
\text { acciones } \\
\text { intensas } \\
\text { pero no } \\
\text { violentas }\end{array}$ \\
\hline
\end{tabular}

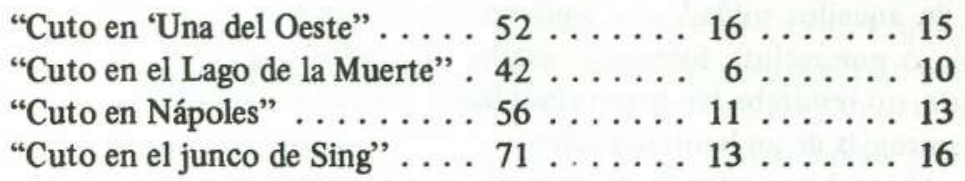

Detengámonos um poco más en la autonomía de este muchacho. No en vano, "Cuto" es, en su época y en España, el representante más caracterizado de este arquetipo del adolescente que se basta a sí mismo. Son mínimas las referencias a un entorno familiar; y más todavía a un enraizamiento en unas circunstancias determinadas. "Cuto" es, pues, un desarraigado tanto en el espacio como en el tiempo (hemos aludido a su actuación en ambientes separados entre sí tanto por miles de kolómetros como por decenios). De esta manera encarna un viejo mito: el del "eterno niño" ("Peter Pan"). Reforzado por los factores, tan sugestivos, de la autosuficiencia aventurera.

Este muchaco, por tanto, no depende de nadie (exceptuando, ino faltaba más!, la voluntad de su creador). No hay adultos que le sometan. A la inversa, él suele someter con frecuencia a los adultos (a los malhechores, a los traidores, etc.) No hay barreras que le detengan: aparece en todas las partes del mundo, en una época en que los viajes no estaban al alcance de tanta gente como hoy, entendiéndose siempre normalmente con quien se tercie, como si no hubiera existido una torre de Babel. No hay enemigos que se le resistan, pues les vence a todos, según las infalibles reglas del género de aventuras y la exigencia mercadológica (no se puede matar a un personaje aplaudi-

${ }^{16}$ En el apartado de acciones de violencia incluímos aquéllas en que un personaje encañona a otro con un arma de fuego, le amenaza físicamente de cualquier otro modo $o$, en suma, se propone atentar contra su integridad; además de las consabidas tomas de puñetazos, luchas, etc. En cuanto a las que denominamos acciones intensas, pero no violentas precisamente, se trata de las persecuciones, saltos y alardes físicos de todo tipo que no tienen como objetivo directo causar un daño al prójimo, así como las luchas entre animales o elementos de la naturaleza. 
do $=$ que da dinero). Se trata de la liberación más completa. Ningún programa de emancipación juvenil hubiera of recido más. Los chicos de su edad - todos ellos sujetos, limitados y subordinados - no podían dejar de gozar identificándose con un personaje semejante: pues por ella les parecía liberarse también - "un poco..." - a sí mismos.

"Cuto" es fruto de una tradición muy larga, como hemos indicado, pero también de una experiencia viva reciente. En la guerra española habían sido militarizados en ambos bandos muchos adolescentes, casi niños, que también hubieron de actuar como adultos (y matar...) Jesús Blasco había estado también movilizado, aunque no fuera entonces de los más jóvenes. El modelo de aquellos soldados - aquí no importa que lo fueran por convicción propia o por recluta forzosa - estaba muy próximo para todos. Por consiguiente, no resultaba tan inverosímil hallar a un chico asumiendo responsabilidades propias de un hombre hecho.

Ahora bien, además de depender del pasado, tanto remoto como próximo, el personaje se relaciona con el futuro. El propio Jesús Blasco nos comentaba cómo sus fantasías de entonces, al dibujar escenas en que "Cuto" conducía un automóvil llevando a su lado a uma chica bonita, se han realizado con toda naturalidad en la generación siguiente.

La pujanza de Jesús Blasco, que en aquellos años dio además "la alternativa" artística a sus hermanos - éstos comienzan a dibujar también en $E l$ Gran Chicos -, no debe eclipsar la considerable personalidad de Emilio Freixas, si bien sus trayectorias biográficas habían sido muy diferentes. Freixas llegaba al relato gráfico muy baqueteado y sobre el contenido de sus aventuras, así como sobre el clima de la época, es elocuente el recuerdo de su entrada en Chicos:

"Verá, durante la guerra, yo había presentado una instancia a cierto ministerio para intentar ganarme el pan necesario para mis hijos. Al terminar la contienda civil, esto no me benefició. Todo lo contrario. Fue cuando al pasar a manos de las autoridades dio lugar a un malentendido. Me tacharon de republicano. En fin, lo que sí fue es que José María Huertas Ventosa me dijo: 'Trabaja para 'Chicos'. Vas a crear un personaje que yo te voy a escribir. Verás, de esta forma se acabarán los problemas. El personaje será un coronel que tiene por ayudante a su sobrinho, falangista, y a un pequeño botones'. Y aquí comenzó la primera historieta del coronel Bustamente, Chatillo y Federico. Se llamaba 'El país de las arenas'."17

${ }^{17}$ Francisco de la Fuente: "Emilio Freixas. Entrevista", en Xanadú, Homenaje a Emilio Freixas, p.12. Sucesor de E, Meseguer Editor. Barcelona, 1971. 
No vamos a afirmar que las reiteradas muestras de militarismo en el tebeo de la época se deban a anécdotas semejantes. Pero es evidente que la preponderancia de semejante estamento en el país de la inmediata posguerra condicionó argumentos, conductas e incluso rasgos accidentales. En El Gran Chicos no se disimula una permanente admiración hacia las cualidades militares, que se manifiesta en el reiterado empleo del adjetivo "bizarro" - enconces, muy en boga -, aplicado precisamente a personalidades del ejército: "Tres bizarros oficiales de marina..." (en "Máscara Roja", de Adriano Blasco); "Y el bizarro teniente emprendió el vuelo solo" (en "El portaaviones aereo", del mismo Adriano). El "Capitán Misterio", de Freixas, se titula así por exclusivas razones de prestigio: equivale a decir, en una sola palabra, que el personaje es valeroso, abnegado e invicto. Más divertido resulta el problema con que se torpezó Marisa Villardefrancos, guionista de "Máscara Roja", cuando la marcha del relato abocó a que el protagonista propinase un soberano puñetazo al comandante de un submarino. La guionista le hizo decir, en la acción misma de descargar el puñetazo:

- Yo admiro a los soldados, pero creo que no se debe destruir el mundo... Usted, con su actitud, me obliga...

Hay una pugna entre la admiración incondicional al militar, exigida por el momento político, y el pacifismo, en cuanto tendencia personal de muchos autores de tebeos.

Volviendo a Emilio Freixas, suele trabajar llevado en volandas por la fantasía desbordante de su guionista, José Canellas Casals, a quien sólo alguna vez substituye él mismo - en las aventuras del "Capitán Misterio", por ejemplo -, sin que se pueda ocultar su influencia. Las extremosidades imaginativas de Canellas iban bien a los gustos dibujísticos de Freixas, de modo que el binomio funcionaba satisfactoriamente, Tan sólo cuando Canellas "queda solo" o "actúa a cuerpo limpio", es decir, cuando larga un texto algo extenso, el énfasis propio de la época se desborda hasta más allá de lo tolerable. Así, en "El duende de Manhattan" se llama a "Sir Black" en tres ocasiones nada menos que "el sublime brujo". El texto final de "Lucharé por ti" pudiera pasar a una antología de la cursi: "Y cinco años después, el fruto tomó la dulcísima forma de uma boda embalsamada de azahar, decorada por el traje a cuadros de Jenks y el cuadro emotivo de todos sus amigos mostrando la más honda gratitud".

Las historietas de Emilio Freixas son muy diversas en la muestra estudiada. En cuanto a la distribución en ellas de los recursos dinámicos, queda como sigue: 


\section{Tabla X}

$\begin{array}{ccc}\begin{array}{c}\text { Número } \\ \text { total de }\end{array} & \begin{array}{c}\text { Número } \\ \text { viñetas con }\end{array} & \begin{array}{c}\text { viñetas con } \\ \text { acciones }\end{array} \\ \begin{array}{c}\text { viñetas del } \\ \text { relato }\end{array} & \begin{array}{c}\text { acciones de } \\ \text { violencia }\end{array} & \begin{array}{c}\text { peronsas } \\ \text { gráfico }\end{array} \\ & & \text { violentas }\end{array}$

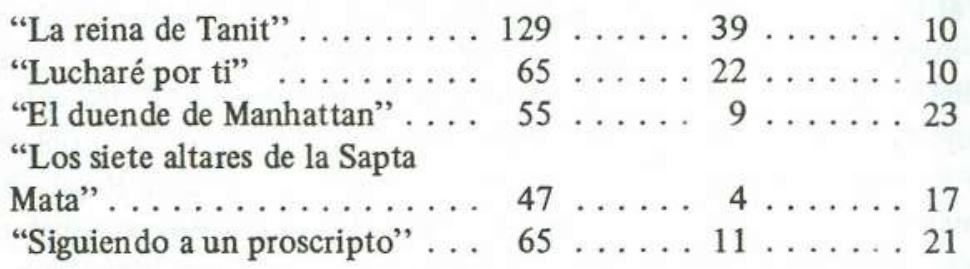

El estilo de Freixas, que algunas veces hemos considerado tardo-modernista, se amolda a la creación de tipos femeninos en la línes de lo que en otro tiempo se llamó "la mujer fatal". En cambio, cuando necesita plasmar la ingenuidad femenina, no le queda más remedio que infantilizar a sus heroínas: con lo cual ya no son mujeres, sino niñas, lindas rubitas inofensivas. El dibujante debía hallarse con toda seguridad a gusto realizando personajes como "La reina de Tanit", llamada Nerea. Esta es hermosa: pero su hermosura simboliza precisamente su peligrosidad. Es la concepción de los antiguos ascetas: la belleza de la mujer como cepo para el varón o envoltura engañosa de los sentimientos más sórdidos. Menos mal que el "Capitán Misterio" consigue derrotarlos, e incluso añade a sus altas cualidades supuestamente militares el carisma del predicador, ya que en la última página del relato gráfico sermonea eficazmente a la seductora reina (!). La indiferencia sexual del protagonista ante Nerea - que se sugiere - le aproxima también a los héroes de la leyenda cristiana, en quienes se había ponderado tanto esta clase de vencimientos. Por lo demás, es un tema mitológico común a otras tradiciones religiosas: la mujer puede neutralizar la "furia guerrera" del héroe. ${ }^{18}$

La misma misoginia aparece en la aventura anterior, "En las selvas oceánicas". La última viñeta de ésta presenta al buen doctor, que teniendo abrazada a su hija - una clásica "muñequita rubia" de Freixas - se dirige así al héroe encapuchado:

- Capitán, ha salvado usted al mundo de una gran amenaza. Ahora reconstruiremos el hospital. Quédese con nosotros y no corra más peligros.

${ }^{18} \mathrm{Cf}$. Mircea Eliade: Iniciaciones misticas, p.148. Taurus Ediciones. Madrid, 1975. 
A lo cual responde él:

- Gracias, doctor, pero creo que al lado de su hija correría un peligro más grande que los de la selva.

La reticencia respecto de la mujer y la incomprensión del amor humano son demasiado frecuentes, no sólo en la revista que ahora nos ocupa, sino en la producción tebeística global de la época. Acaso fuera simplista echarle la culpa exclusivamente a la censura. Probablemente ha intervenido en ello también un largo acarreo social de impreparación, romanticismo invidente, instrumentalización de la mujer, incomunicación entre los sexos, etc. etc.

Lo cierto es que cuando el amor aparece en estos relatos gráficos es casi siempre como a hurtadillas. $\mathrm{Y}$ en una función que pudiera denominarse "ornamental": el guionista: - especialmente M. Villardefrancos, i que es mujer! - parece estimar que "hace bonito" y lo cuela como puede: es decir, no lo afronta en ningún caso cara a cara, sino que lo improvisa, lo yuxtapone, con lo cual se tergiversa de hecho tanto la belleza como la trascendencia y la realidad misma del amor humano. En "Misterio en el mar" es a todas luces un complemento, un elemento-tapón que se coloca allí donde falta una pieza: a novia perdida, novia improvisada. Análoga improvisación, en otras circunstancias, hay en los amores que aparecen en "El enlace", "iTinieblas!" y "Cinco hombres". Las uniones son todas igualmente impremeditadas: el hecho de salvar a una chica de algún peligro parece convertirse, automáticamente, en un compromiso de boda (en "Cinco hombres" la salvada es nada menos que una extraterrestre a quien apenas se ha tratado); igualmente, unas contadas horas de convivencia producen en "El enlace" un enamoramiento fulminante; o en "iTinieblas!", donde basta que una pareja de jóvenes comparta la aventura para que éstos se vean conduzidos por el inflexible guionista a una consecuencia matrimonial...

Debido a la compartimentación entonces vigente entre la esfera del chico y la de la chica, parece que sólo pudieran coincidir en un terreno común para el matrimonio. Quedando prácticamente ignoradas otras clases de relación: amistad, compañerismo, colaboración profesional o recreativa, etc. A menudo, la joven aparece en el relato gráfico como un simple motivo estético (como en "Jack Logan"): pero su presencia conlleva la relación que habrá de ser fatalmente matrimonial. Se trata de una mujer-objeto-boda.

Por otra parte, no siempre los guionistas se atreven siquiera a mencionar determinadas realidades más o menos vinculadas con el amor. Es frecuente que las disimulen. En "El enlace" se dice a unos novios que han quedado en los asientos traseros del avión: "En vez de hablar con Helen...", cuando el lector menos avisado podría suponer que, más que hablar precisamente, estarían "arrullándose" o "acariciándose"...

Estas observaciones se corroboran en el estudio cuantitativo. Sobre el 
total de viñetas de los relatos gráficos en la muestra estudiada, el amor humano aparece tan sólo en un 1'3\% de las mismas (= 25 viñetas). A ellas habría que añadir 13 viñetas más con alusiones de pasada; pero consideramos discutible esta última cifra, pues resulta muy afectada por las 7 viñetas de una historieta humorística en que "Cuto" se dedica furiosamente a deshojar margaritas. Como quiera, la presencia del tema amoroso es exigua. Ante una cuestión tan importante para la vida del individuo y para la sociedad, los adolescentes de 1940-50 estaban completamente abandonados a sí mismos.

El recurso a la violencia, que hemos considerado en algunas tablas parciales, queda resumido como sigue en una tabla general, abarcando todas las historietas de aventuras de la muestra estudiada:

\section{Tabla VI}

Número total de viñetas: 1833 (se han restado las correspondientes a los tebeos que quedan incompletos)

Número de viñetas con acciones de violencia: 351 (=18‘9\%)

Idem, con acciones intensas pero no violentas: $327(=17$ ' $8 \%)$

Unas proporciones prudenciales: suficientes para mantener la vivacidad y el dinamismo deseados por el público, pero sin incurrir en exceso. Los dirigentes de El Gran Chicos, sinceramente preocupados por este aspecto, lo controlaron, manteniéndolo en un encomiable equilibrio.

Lo mismo que habíamos comprobado en casos anteriores, la realidad brilla por su ausencia en los relatos gráficos de El Gran Chicos. El único personaje que parece aproximarse a ella - engañosamente - es el adolescente autosuficiente, en particular "Cuto". Pero él mismo se encarga de contradecir a menudo ese espejismo. La realidad aprehensible en los tebeos es otra. Deliberadamente o no, se ha escamoteado a los muchachos la vida inmediata que les está aguardando a la vuelta de muy pocos años.

Las consecuencias de este escamoteo pertenecen ya a la experiencia adulta de la generación lectora de los tebeos comentados. Pero el historiador puede preguntarse, mientras tanto, si acaso el propio cuerpo social del país no había vivido también, en su orden propio, una experiencia semejante: bajo un régimen fuera del tiempo y del estilo europeos, con una escala de valores formada en una guerra civil e impuesta como resultado de la misma, haciendo problema de hechos que no lo eran estrictamente y esquivando otros problemas mucho más acuciantes, etc. etc. Probablemente, la correspondencia entre el contenido de los tebeos y la situación general imperante era mucho más estrecha de lo que hasta ahora se había venido suponiendo.

*Centro de Estudos Postuniversitários

Paris, 118

08036, Barcelona - Espanha. 